\title{
Impact of Urbanisation: A Comparative Overview of Four Mega Cities In India
}

\author{
Pooja Sharma \\ Assistant Professor, Daulat Ram College, \\ University of Delhi
}

\author{
Sumit Sharma \\ Department of Environment Studies, \\ University of Delhi
}

\begin{abstract}
With the emerging growth in population and increasing urbanisation characterized by growing number of vehicles in mega cities has led to a detrimental impact on environment and climate across all mega cities in India. This excessive urbanisation has overloaded the limited scarce resources and deteriorated the environmental quality, affecting natural resources and environment. This paper overviews the trend of urbanisation captured by increasing population and variations in temperature from period 1951 to 2001 for the four mega cities in India The paper also examines the trends observed in various indicators of climate change like temperature, rainfall four mega cities of India namely Delhi, Kolkata , Chennai and Mumbai for the period 2001 to 2009 .The paper clearly exhibits the impact on climate change by observing the trends in temperature and precipitation .This impact is captured by computing the correlations between the urbanisation and climate change variables measured as temperature signifying that population holds a very strong significant correlation with temperature variation in all the three mega cities ruling out Delhi. Further the correlation between population, vehicles, temperature humidity and rainfall is computed for Delhi and it is concluded that the rise in population and urbanisation captured by number of vehicles have a positive and high correlation on percentage of humidity as an indicator of climate.
\end{abstract}

Keywords: urbanisation, climate, correlation

\section{INTRODUCTION}

The notion of growth and development is associated with movement of population from rural areas to urban areas in search of better life and living standards. But unfortunately this influx of population further puts pressure on limited resources of urban cities. India has observed a tremendous economic growth coupled with population growth and thereby leading to excessive urbanisation. Economic growth on one hand has increased agricultural and industrial growth and at the same time on the other hand tremendous increase in population has put an excessive pressure on limited resources of urban areas. In India metropolitan cities have undergone immense urbanisation consequently deteriorating environmental quality of these cities.

According to 2011 census $27.82 \%$ of Indian population lives in urban setup and three of the world's ten most populous cities are in our country namely Mumbai, Delhi and Kolkata. The recent trend of increased urban growth has outstripped the limited capacity of these cities to provide basic services as a result we are facing more serious challenges like environmental degradation which include increasing air and water pollution, decreasing forest cover, wetlands and croplands, decreasing biodiversity, increased brown field areas and inadequate sewage and waste disposal ${ }^{1}$.Mohan, Manju (2011 $)^{2}$ evaluated

\footnotetext{
${ }^{1}$ DES, UN. "World economic and social survey 2013: sustainable development challenges." United Nations, Department of Economic and Social Affairs, New York (2013).

${ }^{2}$ Mohan, Manju, et al. "Dynamics of urbanization and its impact on land-use/land-cover: A case study of megacity
} 
Delhi on the basis of land use and concluded that Delhi has expanded by $17 \%$ on the expense of agricultural land, waste land and water bodies between 1997 to 2008. During the same period the forest cover of Delhi has increased by $0.5 \%$ and water bodies have decreased by $52.9 \%$. Rao,AK Jaswal,MS Kumar, Mausam, $(2004)^{3}$ carried out a linear trend analysis for different meteorological parameters in 15 selected cities shows that population density, tall buildings, vehicular and industrial pollution are the main players which is controlling the urban climate. General trend in these cities is of decreasing sunshine, cloud cover and wind speed while there is an increase in temperature, rainfall and humidity.

Kundu (2011) ${ }^{4}$ pointed out that the process of urbanisation in India is more oriented towards larger cities. The reason quoted was that the larger cities are more efficient in generating growth and attracting investments whereas smaller towns located away from the emerging global centres of growth have not attracted much private investment and hence has reached economic stagnation. Bhagat (2011) $)^{5}$ figured out that the declining trend of urbanisation in 90 's is reversed in the last decade and the level of urbanisation increased faster during 2001-11(from $286 \mathrm{~m}$ in 2001 to $377 \mathrm{~m}$ in 2011) period mainly because of rural to urban migration and large base of urban population which has implications for providing urban infrastructure and amenities. Dhode, Dhorde and Gadgil (2009) ${ }^{6}$ examined the effect of urbanisation on minimum and maximum temperature general trend found is increase in average temperature with different rates in different season except Mumbai where minimum temperature during monsoon and winter showed a significant decrease. Bherwani, Hemant and Kumar ${ }^{7}$ used the time series analysis on temperature profile of Mumbai city was carried out

Delhi." Journal of Environmental Protection 2.09 (2011): 1274.

${ }^{3}$ Rao, GS PRAKASA, A. K. Jaswal, and M. S.

Kumar. "Effects of urbanization on meteorological parameters." Mausam 55.3 (2004): 429-440.

${ }^{4}$ Kundu, Amitabh. "Trends and processes of urbanisation in India." (2011).

5 Bhagat, R. B. "Emerging pattern of urbanisation in India." Economic and Political Weekly 46.34 (2011): 10-12.

${ }^{6}$ Dhorde, Amit, and Anargha Wakhare. "Evidence of long-term climate change at major cities of India during the twentieth century." Int J Clim Change Imp Res 1 (2009): 15-41.

${ }^{7}$ Bherwani, Hemant, R. S. Patil, and Rakesh Kumar. "City Size and Change in Temperature profile: Study on Major Indian Cities." and triple exponential smoothed curve was fitted in order to demonstrate the trend of temperature profile of the city and it was further forecasted using the time series equation and general methodology of curve fitting.

This paper specifically focuses on the four of the India's mega cities namely Delhi, Kolkata, Chennai, and Mumbai which have distinctly gone through tremendous urbanisation. Thepaper would over view the trend of their urbanisation from 1951 to 2011, establishing the impact on industrial and agricultural growth and further reinforcing a strong correlation between the urbanisation and the climate change which is captured by changes in the temperature and precipitation.

\section{PROFILE OF MEGA CITIES: A BACKGROUND}

Delhi is located in northern India between the latitudes of $28^{\circ}-24^{\prime}-17^{\prime \prime}$ and $28^{\circ}-53^{\prime}-00^{\prime \prime}$ North and longitudes of $76^{\circ}-50^{\prime}-24^{\prime \prime}$ and $77^{\circ}-20^{\prime}-37^{\prime \prime}$ East. Delhi shares bordering with the States of Uttar Pradesh and Haryana. Delhi has an area of 1,483 sq. kms. Delhi is bounded by the Indo-Gangetic alluvial plains in the North and East, by Thar Desert in the West and by Aravalli hill ranges in the South. The terrain of Delhi is flat $^{8}$

The total area of Mumbai is $603.4 \mathrm{~km} 2$. Of this, the island city spans $67.79 \mathrm{~km} 2$, Mumbai is bounded by the Arabian Sea to the west. The city has an average elevation of $14 \mathrm{~m}$. The original seven islands of Bombay consisted of 22 hills. Most of them were razed to fill in the shallows to connect the islands?

Kolkata is located in the eastern part of India. It has spread linearly along the banks of the Hooghly. The Kolkata has an area of 185 square kilometres. The city is near sea, with the average elevation being 17 feet. The whole area is in the Ganges and is monotonously plain. The Bengal coastline is about 60 miles to the south. The Sundarbans National Park starts within

${ }^{8}$ Dupont, Véronique DN. "The dream of Delhi as a global city." International Journal of Urban and Regional Research 35.3 (2011): 533-554

${ }^{9}$ Jahanshahi, Asghar Afshar, et al. "The relationship between government policy and the growth of entrepreneurship in the micro, small \& medium enterprises of India." Journal of technology management \& innovation 6.1 (2011): 66-76. 
$100 \mathrm{~km}$ south to the city. Most of the city was originally marshy, wetlands ${ }^{10}$

Chennai is located on the South Eastern coast of India in North Eastern part of the Indian state of Tamil Nadu. Its geographical coordinates is $13^{\circ} 04^{\prime} \mathrm{N}$ latitude and $80^{\circ} 17^{\prime} \mathrm{E}$ longitude. An urban city, it is located along the shorelines of Coromandel Coast, The average elevation of the city is 6.7 metres while the highest point in the city is at $60 \mathrm{~m}$.

\section{TRENDS IN URBANISATION IN MEGA CITIES}

Most of the mega cities have been trapped in the clutches of continuous and consistent migration happening from nearby rural areas even from areas much farther. The most common reason for this movement is the search for employment and better quality of life .Delhi being the capital city of India has observed a tremendous increase in population since 1951.It is very interesting to observe that the population in Kolkata is higher than the population in Mumbai. The rate of growth of population is much higher in Kolkata than Mumbai. There exists a wide difference in population in Chennai as compared to other mega cities Moreover the rate of growth of population is not showing a larger increase in case of Chennai.

Fig 1: A Comparison of population in lacs in mega cities from 1951 to 2011

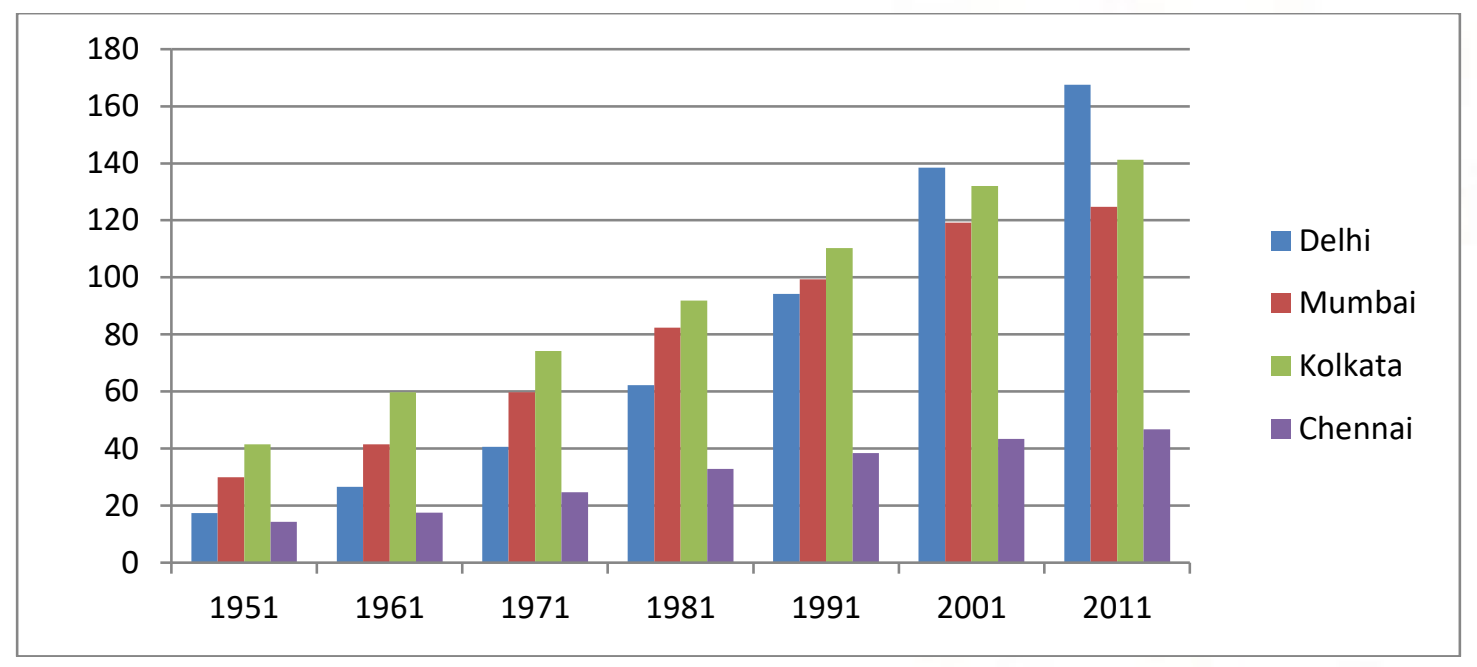

\section{Author's Calculation}

Source: Government of India (2011) - Provisional population totals, urban agglomerations and cities planning commission of India.

When we examine the urban agglomeration mainly cities having population more than a million, taking the index in 1951 as 100 , Delhi has again showed an acutely a very high rise in population In this case Mumbai growth of population is higher than Kolkata.

\footnotetext{
${ }^{10}$ Banerjee, Tridib, and Sanjoy Chakravorty. "Transfer of planning technology and local political economy: a retrospective analysis of Calcutta's planning." Journal of the American Planning Association 60.1 (1994): 71-82.
} 
Fig 2: Indices of Population Growth of Urban Agglomeration /Cities Having the Population More Than a Million in 2011

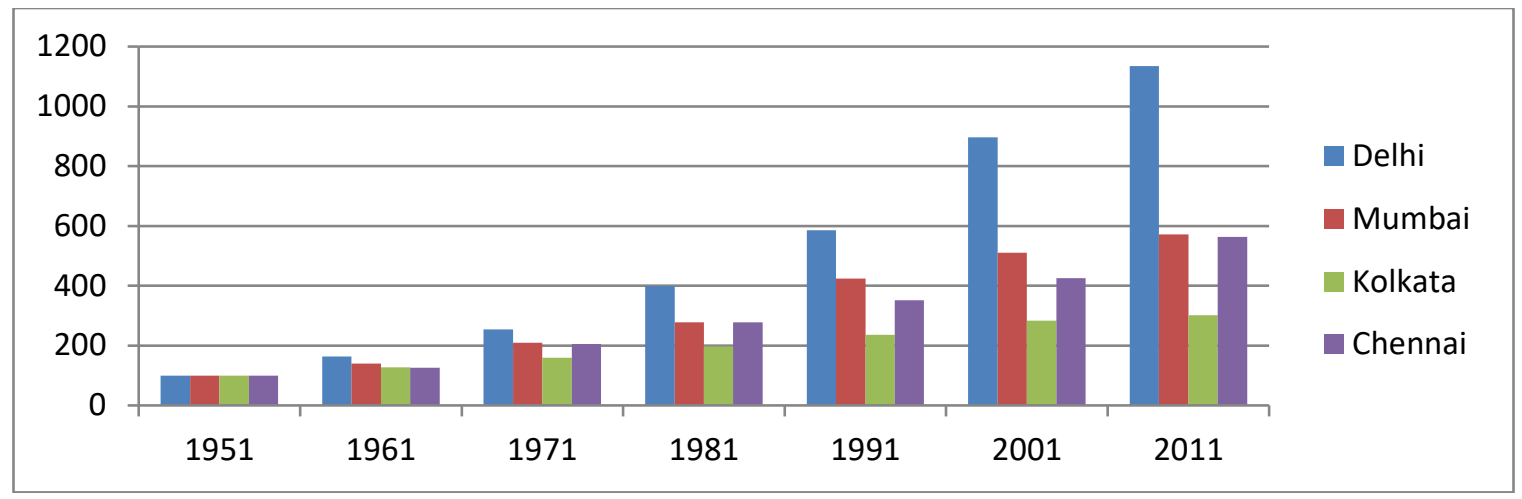

\section{Author's Calculations}

Source: Author's Calculation Government of India (2011) - Provisional population totals, urban agglomerations and cities planning commission of India.

\section{TREND IN TEMPERATURE}

One of the most crucial impacts of urbanisation on climate is the wide variations being observed in the temperature across most of the metropolitan cities. In case of Delhi there is sudden dramatic rise in variation of Annual mean temperature in 1981 but this variation declined still maintaining a rising trend. While the rest of the cities have also maintained a rising trend in the variation in temperature since 1951.

Fig 3: Variation of Annual Mean Temperature (Temperature degree centigrade)

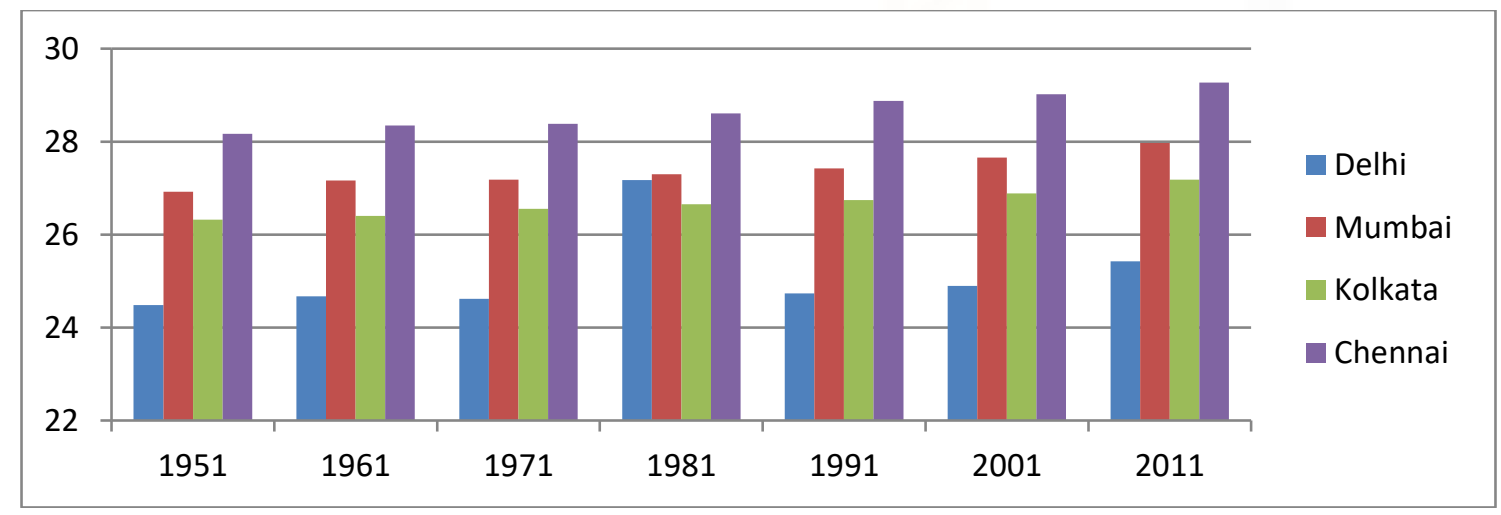

\section{Author's Calculation}

Source: Goddard Institute of Space Studies (GISS), National Aerounital and Space Administration (NASA)

\section{TRENDS IN GROWTH IN NUMBER OF VEHICLES}

The data clearly depicts that the number of registered vehicles in Delhi is maximum .between the period 2001 to 2009. According to the data the growth of vehicle in Chennai city during this period is higher than Mumbai and Kolkata, while the growth of vehicles in Kolkata is lowest among all these metropolitan cities during this time period. 
Fig 4: Total Registered Motor Vehicles in Metropolitan Cities (as on 31st March) in thousands

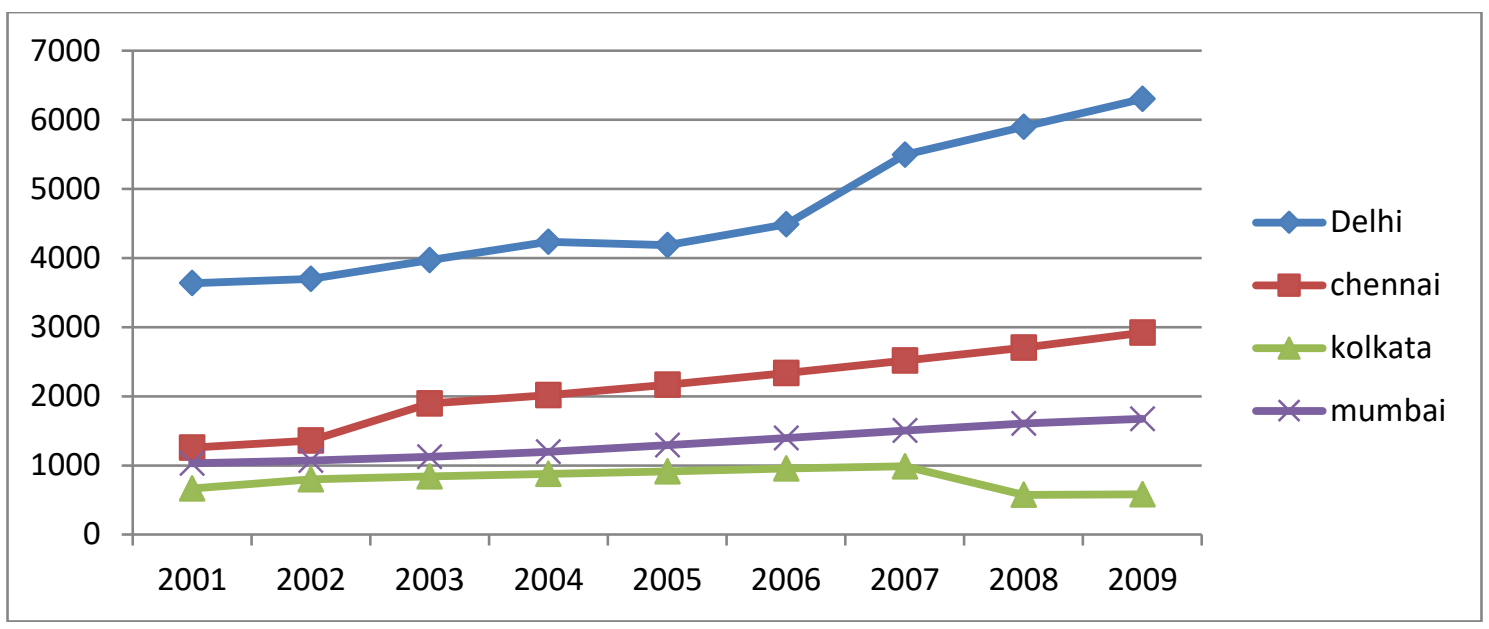

Author's Calculation

Source: Road Transport Year Book (2007 - 2009)

\section{CORRELATIONS}

Table 1: Results of Correlation between Population and Temperature

\begin{tabular}{|l|l|l|l|l|l|l|l|l|l|}
\hline & & Delhi & \multicolumn{3}{|l|}{ Mumbai } & \multicolumn{2}{l|}{ Kolkata } & & \multicolumn{2}{l|}{ Chennai } \\
\hline & & $\log P$ & $T$ & $\log P$ & $T$ & $\log P$ & $T$ & $\log P$ & $T$ \\
\hline Delhi & $\log \mathrm{P}$ & 1.0000 & & & & & & & \\
\hline & $\mathrm{T}$ & 0.2879 & 1.0000 & & & & & & \\
\hline Mumbai & $\log \mathrm{P}$ & 0.9893 & 0.3605 & 1.0000 & & & & & \\
\hline & $\mathrm{T}$ & 0.9456 & 0.2183 & 0.8991 & 1.0000 & & & & \\
\hline Kolkata & $\log \mathrm{P}$ & 0.9925 & 0.3178 & 0.9953 & 0.9257 & 1.0000 & & & \\
\hline & $\mathrm{T}$ & 0.9570 & 0.2690 & 0.9197 & 0.9858 & 0.9325 & 1.0000 & & \\
\hline Chennai & $\log \mathrm{P}$ & 0.9886 & 0.3707 & 0.9986 & 0.8965 & 0.9904 & 0.9245 & 1.0000 & \\
\hline & $\mathrm{T}$ & 0.9782 & 0.2259 & 0.9411 & 0.9771 & 0.9545 & 0.9759 & 0.9425 & 1 \\
\hline & & & & & & & & & \\
\hline
\end{tabular}

Source: Author's Calculations

The correlation data clearly emphasis a crucial deduction that when the log of population is correlated to temperature data of all these mega cities, it is visualized that there exists a very high correlation between the population growth and annual average temperature .However this result is not true in case of Delhi, where the correlation is very week between population and temperature only 0.28 . While rest of the cities show a very high correlations between the log of population and annual average temperature for the period between 1951 to 2001.

\subsection{Correlations between Population, Temperature, Humidity and rainfall: Case of Delhi}

By observing the data of monthly and annual temperature and humidity in Delhi it is observed that percentage of humidity has been rising in Delhi consistently, however the maximum temperature has maintained a constant level. As far as rainfall is concerned the annual rainfall has shown a steep rise in 2003 but further declined in 2004 further rising consistently. 
Fig 5: Monthly and Annual Temperature, Relative humidity and Rainfall

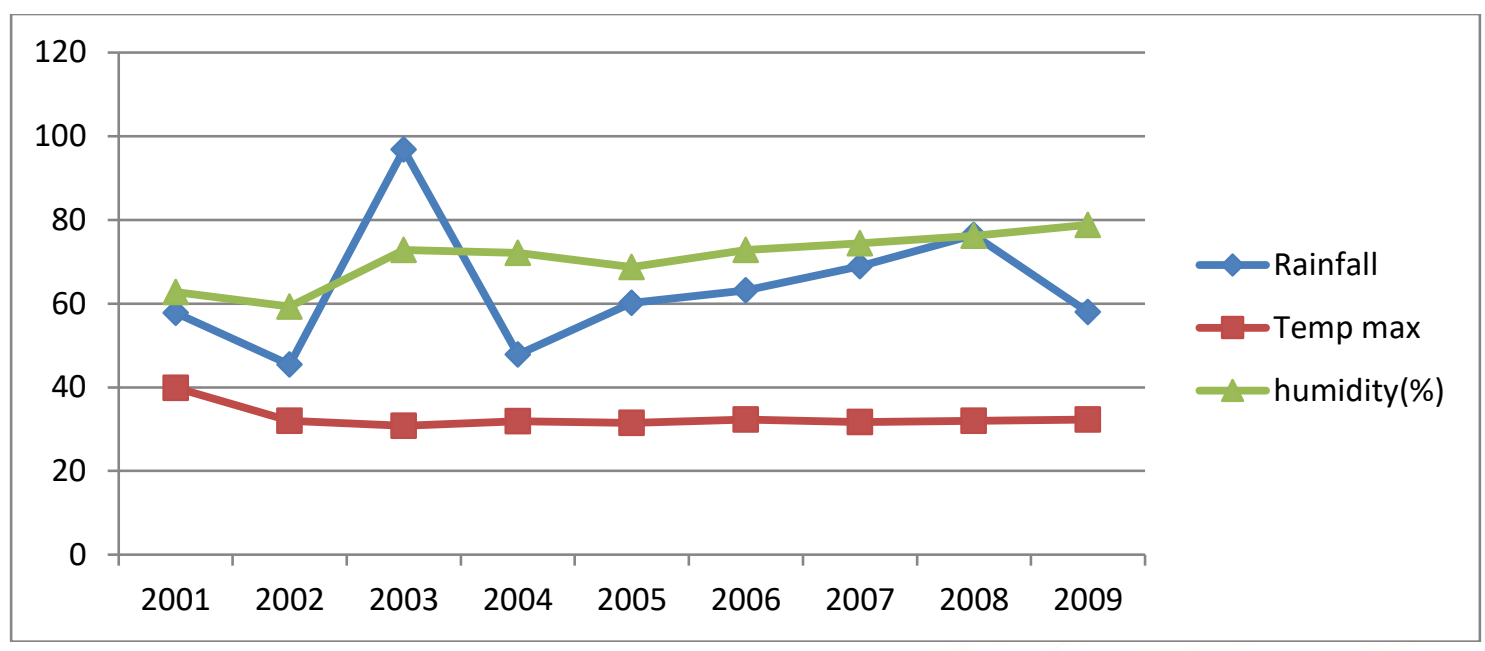

Author's Calculations

Source: Regional Meteorological Department, New Delhi Note: Relative Humidity at 08.30 IST

Table 2: Results of Correlations between Projected population, Rainfall, Temperature, Humidity and no. of Vehicles

\begin{tabular}{|l|l|l|l|l|l|}
\hline & & & & & \\
\hline & Proj P & Rainfall & Temp( max ) & Humidity (\%) & Vehicles \\
\hline Proj P & 1 & & & & \\
\hline Rainfall & 0.1528 & 1 & & & \\
\hline Temp max & -0.462 & -0.2555 & 1 & & \\
\hline $\begin{array}{l}\text { Humidity } \\
(\%)\end{array}$ & 0.8588 & 0.4466 & -0.4629 & 1 & 1 \\
\hline Vehicles & 0.9559 & 0.1621 & -0.3187 & 0.8218 & \\
\hline & & & & & \\
\hline
\end{tabular}

Source: Author's Calculations

The above correlation values hold an important significance in the analysis of impact of urbanisation on climate of a region. The above correlation result is a case of Delhi region. The data for population is taken as projected population data for the period 2001 to 2009 Further the data for the indicators of Climate change in the form of temperature, humidity and rainfall has been used for the period 2001 to 2009. The number of vehicles registered in Delhi for the period 2001 to 2009has been considered as an indicator of urbanisation It can be clearly observed that population and humidity are highly correlated in case of Delhi. . There also exists a strong correlation between number of vehicles and population in Delhi between the period 2001 to 2009 is also considerably high approximately 0.955 . Similarly the correlation between the number of vehicles and percentage of humidity is also significantly high approximately 0.82 .

It is concluded that the rise in population and urbanisation captured by number of vehicles have a positive and high correlation on percentage of humidity as an indicator of climate

\section{CONCLUSION}

In the present era when Climate change has taken the most crucial challenge across all developed and developing countries across world, it is significant to observe the impact of urbanisation on the climate in most of the mega cities in India. This paper reveals that there are considerable amount of harmful 
consequences that the four mega cities have undergone in terms of climate and these effects are due to increasing urbanisation which puts tremendous pressure on limited resources of a region. It is visualized that there exists a very high correlation between the population growth and annual average temperature .However this result is not true in case of Delhi, where the correlation is very week between population and temperature only 0.28 . While rest of the cities show a very high correlations between the $\log$ of population and annual average temperature for the period between 1951 to 2001 . It is concluded that the rise in population and urbanisation captured by number of vehicles have a positive and high correlation on percentage of humidity as an indicator of climate. Finally the need of the hour is to make policies which target a sustainable growth and development keeping in account the cost growth and population entails on environment.

\section{REFERENCES}

1) Banerjee, Tridib, and SanjoyChakravorty. "Transfer of planning technology and local political economy: a retrospective analysis of Calcutta's plans." Journal of the American Planning Association 60.1 (1994): 71-82

2) Bhagat, R. B. "Emerging pattern of urbanisation in India." Economic and Political Weekly 46.34 (2011): 10-12.

3) Bherwani, Hemant, R. S. Patil, and Rakesh Kumar. "City Size and Change in Temperature profile: Study on Major Indian Cities."

4) DES, UN. "World economic and social survey 2013: sustainable development challenges." United Nations, Department of Economic and Social Affairs, New York (2013).

5) Dhorde, Amit, and Anargha Wakhare. "Evidence of long-term climate change at major cities of India during the twentieth century." Int J Clim Change Imp Res 1 (2009): 15-41.

6) Dupont, Véronique DN. "The dream of Delhi as a global city." International Journal of Urban and Regional Research 35.3 (2011): 533-554.

7) Jahanshahi, AsgharAfshar, et al. "The relationship between government policy and the growth of entrepreneurship in the micro, small \& medium enterprises of India." Journal of technology management \& innovation 6.1 (2011): 66-76.

8) Kundu, Amitabh. "Trends and processes of urbanisation in India." (2011).
9) Mohan, Manju, et al. "Dynamics of urbanization and its impact on land-use/land-cover: A case study of megacity Delhi." Journal of Environmental Protection 2.09 (2011): 1274.

10) Rao, GS PRAKASA, A. K. Jaswal, and M. S. Kumar. "Effects of urbanization on meteorological parameters." Mausam 55.3 (2004): 429-440. 